\title{
Spatio-temporal analysis of vegetation and oil spill intensity in Ogoniland
}

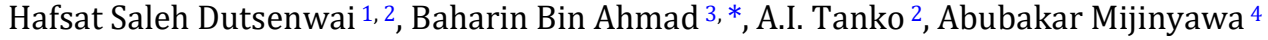 \\ ${ }^{1}$ Department of Remote Sensing, Faculty of Geoinformation and Real Estate, Universiti Teknologi Malaysia (UTM), Johor, \\ Malaysia \\ ${ }^{2}$ Department of Geography, Faculty of Earth and Environmental Sciences, Bayero University Kano (BUK), Kano, Nigeria \\ ${ }^{3}$ Department of Geoinformation, Faculty of Geoinformation and Real Estate, Universiti Teknologi Malaysia (UTM), Johor, \\ Malaysia \\ ${ }^{4}$ Department of Geoscience and Petroleum Engineering, Universiti Teknologi Petronas (UTP), Perak, Malaysia
}

\section{A RT I C L E IN F O}

\section{Article history:}

Received 11 October 2016

Received in revised form

17 February 2017

Accepted 25 February 2017

Keywords:

Spill points

Intensity

NDVI

Spatio-temporal change

\begin{abstract}
A B S T R A C T
Ogoniland, Niger Delta Nigeria is an area that has been subjected to terrestrial oil spills from the beginning of oil exploration in the 1950s till date. Despite many studies and practical efforts by different organizations and multinational companies, oil spills continue to occur and their impacts persist. These oil spills are regarded as the major cause of environmental degradation in the study area. The objective of this study was to ascertain the fact that oil spill is the major cause of environmental changes in Ogoniland using Normalized Difference vegetation Index (NDVI) and statistical methods. Remote sensing satellite data (Landsat 5TM (1984), Landsat 7ETM+ (2013, 2014 and 2015), and geographical coordinates of spill locations were used to observe vegetation dynamics with respect to the intensity of oil spills. For vegetation dynamics, the geographical coordinates were used to observe temporal variations of NDVI values at each spill point while statistical analyses were used to identify the relationships between the intensity of the spills and the changes in vegetation. It was observed that changes in vegetation quality and quantity can be attributed to oil spill occurrences, however, the level of change in vegetation cannot be ascribed to the frequency or intensity of the oil spills. Finally, this study asserts that oil spill is the major cause of environmental changes in the study area.
\end{abstract}

(C) 2017 The Authors. Published by IASE. This is an open access article under the CC BY-NC-ND license (http://creativecommons.org/licenses/by-nc-nd/4.0/).

\section{Introduction}

The Niger Delta region of Nigeria is located in the Atlantic coast of southern part of Nigeria and it is the second largest delta having a coastline area of approximately $450 \mathrm{~km}$ (Anifowose et al., 2008). It is a flood plain of more than $70000 \mathrm{~km}$ that borders the Atlantic Ocean. The Niger Delta consists of about 8600 sqkm of rivers, estuaries, creeks, and stagnant swamps. The Delta mangrove is the largest in Africa covering $1900 \mathrm{sqkm}$. It is regarded as tropical rainforest with diversity of species and is reported to be highly sensitive (Ibeanu, 2000) with relevant abundance of flora and fauna, and even concentration of industrial activities especially extraction of oil and natural gas (Shell, 2015). Due to this, the Niger Delta is extremely exposed to degradation (Adami et al., 2007), but unfortunately

\footnotetext{
* Corresponding Author

Email Address: baharinahmad@utm.my (B. B. Ahmad)

https://doi.org/10.21833/ijaas.2017.04.013

2313-626X/C 2017 The Authors. Published by IASE.

This is an open access article under the CC BY-NC-ND license

(http://creativecommons.org/licenses/by-nc-nd/4.0/)
}

has received little attention from the global media despite the significant impact they have on community health and ecology (UNEP, 2011).

Ogoniland, a part of the Nigerian Niger Delta has been severely and constantly subjected to crude oil spills due to the intense activities carried out by oil companies which causes high concentration of some inorganic cations and anions in the environment indicating high pollution potential (Onwurah et al., 2007). As a result, the farmlands become unsuitable for agricultural purposes and the streams become unacceptable for domestic and industrial purposes (Onwurah et al., 2007; UNEP, 2011). According to Pitkin (2013), the extensive contamination of rivers, groundwater and creeks in Ogoniland (especially in Gokana LGA) causes severe aftermaths on the health of humans and the ecosystem. For example, large mangrove areas have been destroyed and the chronic nature of the contamination prevents recovery.

Past studies on the application of remote sensing data and methods of image processing mostly focused on marine pollution events (Hese and Schmullius, 2009; Fingas, 2012; Reible, 2010). 
Additionally, coastal and marine applications were published with various methods and outcomes through the use of monitoring the extent, drift and type of oil pollution (Hese and Schmullius, 2009; Brekke and Solberg, 2005). However, the monitoring of terrestrial oil spills has received very little attention. This is due to the regional and small scale character of the contaminations of oil spilled on land although they are sometimes complicated by several mixed spectral signatures such as that of vegetation (dead or recovering), or contaminated sands and soils (Hese and Schmullius, 2009). Nevertheless, it is important to study problems of oil spill in the terrestrial environment especially in a country like Nigeria, based on the fact that the country's economy depends highly on oil.

Several studies carried out on remote sensing applications in Nigeria were based mostly on the entire Niger delta, focusing on land cover change analysis. The most commonly satellite data used is Landsat which was used for land cover change analysis (Abbas and Fasona, 2012; Twumasi and Merem, 2006), mangrove, forest and non-forest mapping by Onojeghuo and Blackburn (2011), James et al. (2007) and Fatoyinbo and Simard (2013). Adegoke et al. (2010) analyzed Landsat images for coastal changes. According to Noomen et al. (2012) and Van der Meer et al. (2002), remote sensing techniques and approaches such as vegetation indices are evident in their use for effective detection and monitoring the impacts of hydrocarbon spills on the health of vegetation. Adamu et al. (2013) investigated the potential of vegetation spectral reflectance for detecting oil pollution, Adamu et al. (2014) analyzed BVMIs for detecting their potential in detecting polluted areas and Adamu et al. (2015) used vegetation indices to detect oil spill pollution in the Niger delta. Similarly, Uchegbulam and Ayolabi (2013) used NDVI to indicate land degradation caused by hydrocarbon and human impacts.

Both past and recent studies have shown that oil spill pollution is a major problem which has caused environmental degradation in Ogoniland. This has been associated with the alarming number of spills recorded every year. For example from January 2011 to July 2015, 870 oil spills were recorded Shell (2015). This indicates that although several studies have been carried out in the quest for finding solutions or preventions, the problem of oil spill and associated impacts still remains a major concern in Ogoniland. This has given rise to a question of spatio-temporal relationships that exist between the environmental dynamics and the intensity of oil spills. Thus, this study used vegetation as proxy to analyze spatially and temporally the environmental changes in Ogoniland with respect to the intensity of oil spills.

\section{Study area}

Ogoniland, a part of the Nigerian Niger Delta covers about $1000 \mathrm{sqkm}$ in the south eastern part of the Nigerian Niger Delta basin as shown in Fig. 1. It is at located at latitude 4.781 and longitude 7.1548 with a population of almost 832000 according to the National census of 2006. The Ogoni region is divided into four local government areas namely, Eleme, Tai, Gokana and Khana LGAs.

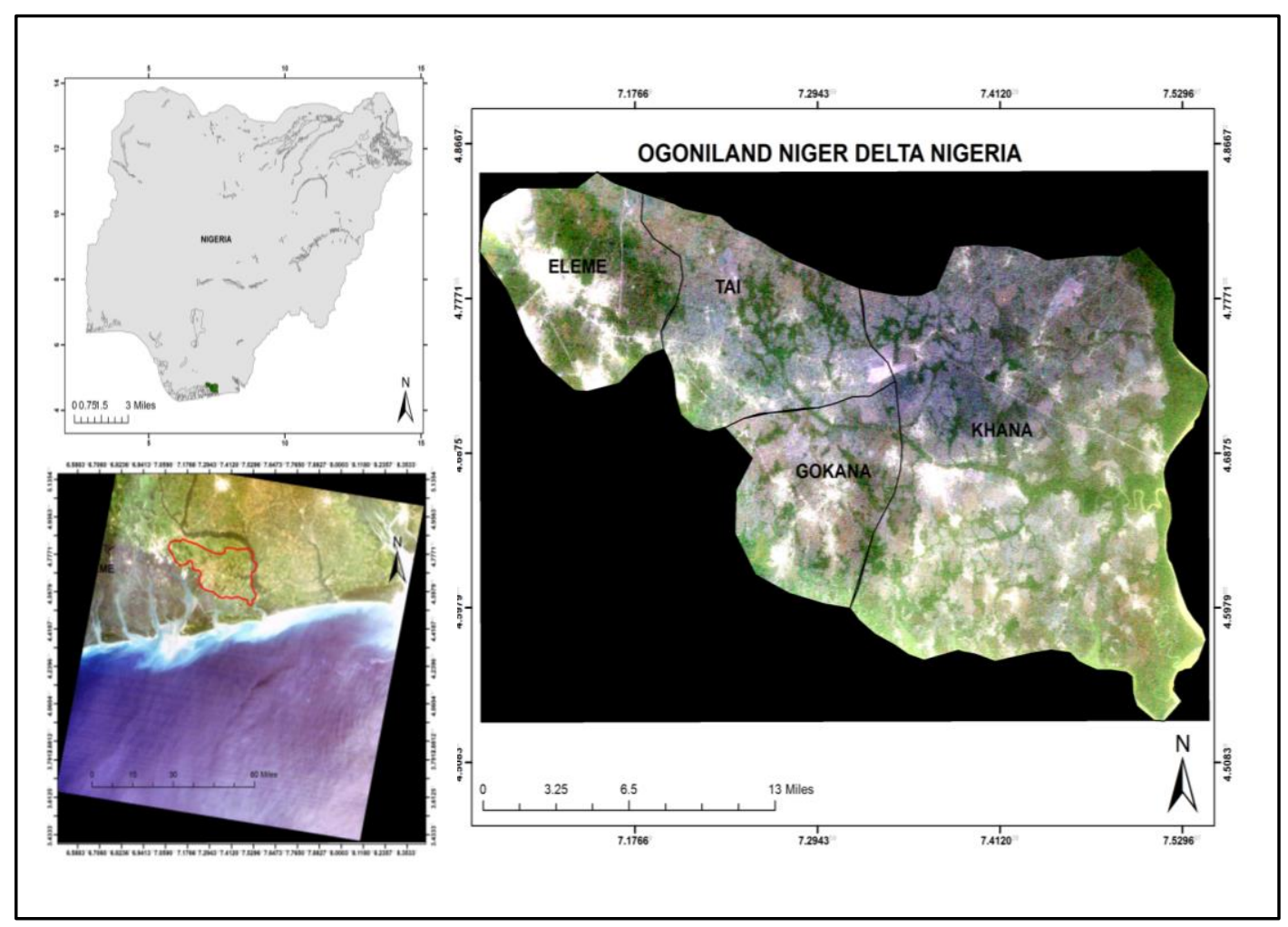

Fig. 1: Study area 


\section{Materials and methods}

\subsection{Data}

Satellite images of Landsat 5TM1984 (will be referred to as the reference image in the subsequent sections), Landsat 7ETM+ 2013 - 2015 were used for deriving and examining information about the study area, Global positioning system (GPS) locations of spill from 2013 to 2015 in geographic coordinates which were obtained from the National Oil Spill Detection and Response Agency, Nigeria (NOSDRAoil spill monitor). Map of oil facilities in Ogoniland which was obtained from the United Nations Environmental Program (UNEP, 2011) was used to digitize oil pipelines in the study area.

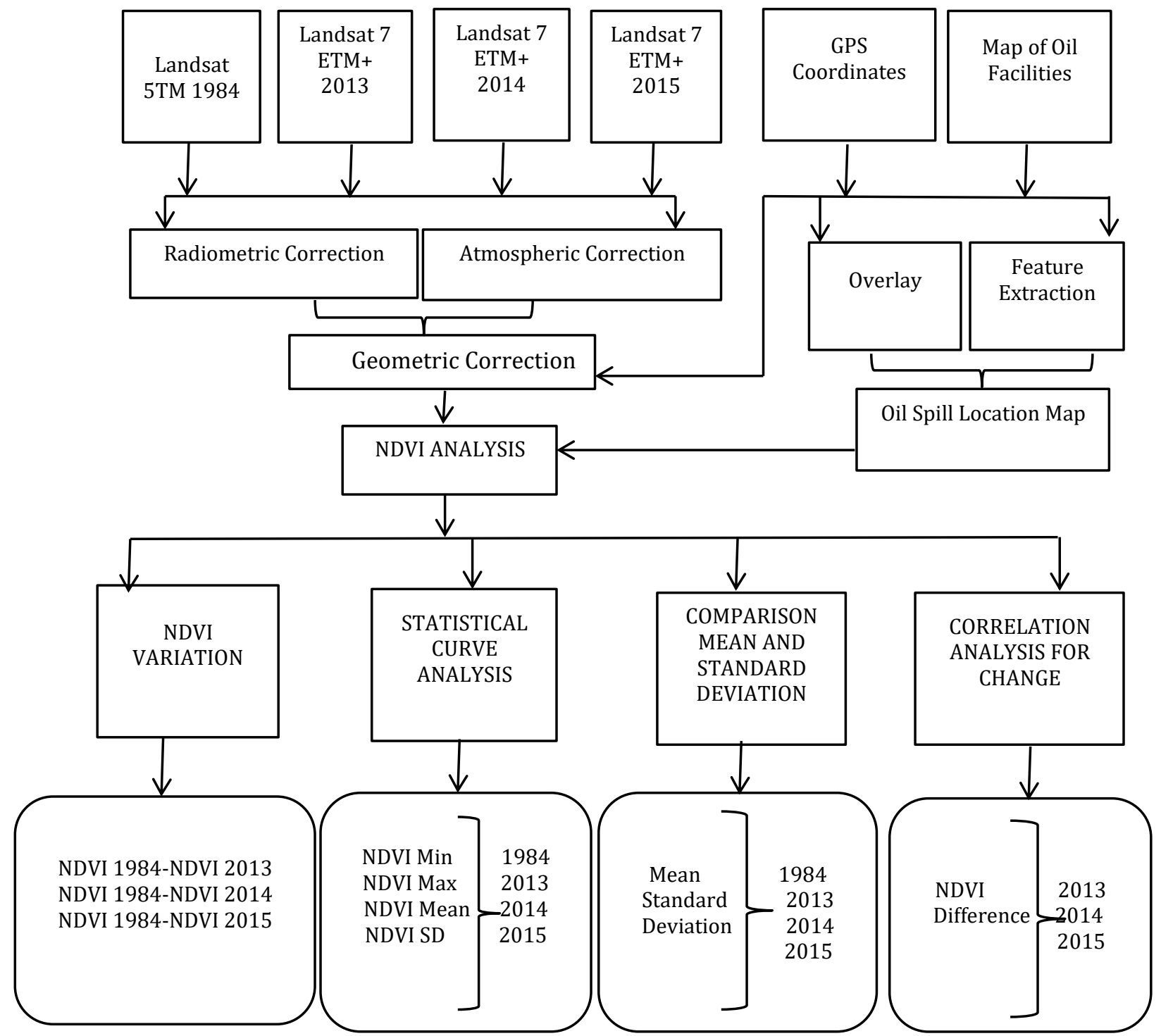

Fig. 2: Flow chart of methodology

\subsubsection{Radiometric and atmospheric correction}

This was used to correct all errors that affect the brightness value of pixels due to changes in scene illuminations, atmospheric conditions, and viewing geometry. In the Landsat images, the first radiometric error that was corrected was the calibration of radiometry between each of the

\subsection{Methodology}

The methodology is divided into data, preprocessing processing and analysis. Fig. 2 presents the flow chart of methodology.

\subsubsection{Preprocessing}

Generally, in order to enhance the quality of the data, various atmospheric and radiometric errors that were caused by external and internal conditions were eliminated. The images were also geometrically corrected. 
reflectance in the ENVI 4.8 using the Landsat calibration function.

\subsubsection{Geometric correction}

The satellite images were registered with ground truth coordinates prior to processing with the ancillary data. This included image to map and image to image registration (using the satellite image to register other satellite images with the aid of ground control points (GCP) and all the data used were converted to the same reference system.

\subsection{Processing}

\subsubsection{Spill location mapping}

All the geographical coordinates being acquired in decimal degrees were converted to points before they were converted to features. This was done to enable the overlay of the location of oil spills on the study area in a three year period. The geographic coordinates were exported from Microsoft Excel to Arcmap in the ArcGIS environment where they were saved in the database and finally converted into features. The spill points (SPs) include 34SPs in 2013, 40SPs in 2014 and 16SPs in 2015. The SPs were used to develop a location map for the oil spills in Arcmap 10.2.2.

\subsubsection{NDVI variation}

The satellite image of 1984 which is highly vegetative was used as a control image by comparing its NDVI values separately with 2013, 2014 and 2015 respectively. This was to assess the level of degradation of each local spill point, as NDVI values are expected to decrease at oil spill points. The comparison was made by comparing the reflectance spectra of each year against the control image separately, and then finally comparing all the spectra in one plot.

The Spill points which were converted from coordinates were overlaid on the NDVI images and NDVI values were taken for all the spill points in the three years (2013 to 2015). These NDVI values were compared with NDVI values from the reference image (Landsat 5TM, 1984) and the differences were calculated by subtracting the NDVI values of each year from the NDVI values of the reference image. The results of the differences were correlated with the spill points using statistical curves, plots of Mean and SD and scatter plots.

\section{Results and discussion}

In this study, the features used to map the oil spill locations are not based on the spectral properties of hydrocarbon, since the data used is multispectral (Landsat). Therefore, the geographical coordinates were directly used to map the spill areas and the reductions in reflection of the visible bands and reduction in the vitality of vegetation (reduced NDVI values at spill points) were used to observe the changes. Oil spill points were converted from geographical coordinates to points by exporting from Microsoft Office Excel 2007 to Arc map 10.2.2 as $\mathrm{X}$ and $\mathrm{Y}$ data. The data were further converted to features as points in order to find their positions on the satellite images. Thirty four spill points in 2013 forty spill points in 2014 and sixteen spill points in 2015 were mapped (Fig. 3) to show the locations and some of the major oil facilities were included. All the spill points were observed to be associated with pipelines, either being along a pipeline or very close to it.

Most of the oil spills occurred in Gokana LGA, followed by Eleme LGA and then Tai LGA with the least number of spills. Moreover, all the spills are observed to be along the SPDC pipelines in operation. On the other hand, in 2014 more spills are located in Gokana LGA, and are more in number compared to Gokana LGA spills in 2013. In 2015, the least number of spills were recorded among the three years $(2013,2014$ and 2015) with only 16 spills. Most of the oil spills occurred in Gokana LGA, followed by Eleme LGA and then Tai LGA with the least number of spills. Moreover, all the spills are observed to be along the SPDC pipelines in operation. On the other hand, in 2014 more spills are located in Gokana LGA, and are more in number compared to Gokana LGA spills in 2013. In 2015, the least number of spills were recorded among the three years $(2013,2014$ and 2015) with only 16 spills. There are fewer spills in all the local government areas except Khana where there is no record of oil spill, being similar to 2013 and 2014 . Almost all the spills occurred along the same locations i.e. along the SDPC pipeline in operation. In all the pipelines, it is visually seen that most spills occurred along the SDPC pipelines in operation followed by a few spills which are not along any of the pipelines.

\subsection{NDVI variation}

In this section, the use of vegetation index to detect variations in oil spill affected areas was evaluated. NDVI was used for temporal analysis of the vegetation at the spill points. The NDVI image (Fig. 4a) of the reference image was compared with the NDVI images (Fig. 4b, c and d respectively) of Landsat 7ETM+ (2013, 2014 and 2015) because of its higher vegetative nature. The quality of vegetation is clearly seen in the range of minimum and maximum values in Fig. 4. It is a part of the objective of this study to determine the variations at the oil spilled areas; hence the NDVI of each spill point in the NDVI images of 2013, 2014 and 2015 was compared with that same point on the reference image. Healthy vegetation is characterized by a reflectance with strong absorption in the red and blue wave length $0.63-0.69 \mu \mathrm{m}$ and $0.45-0.52 \mu \mathrm{m}$ respectively, medium reflectance in the green bands and high reflectance in the NIR bands (Adamu et al., 
2013). Contrarily the spectra will change when the vegetation becomes unhealthy, the reflectance changes by the reduction in the NDVI values. Table 1 shows the spill points and the NDVI of Landsat 7ETM+ 2013 and the corresponding NDVI of the reference image.

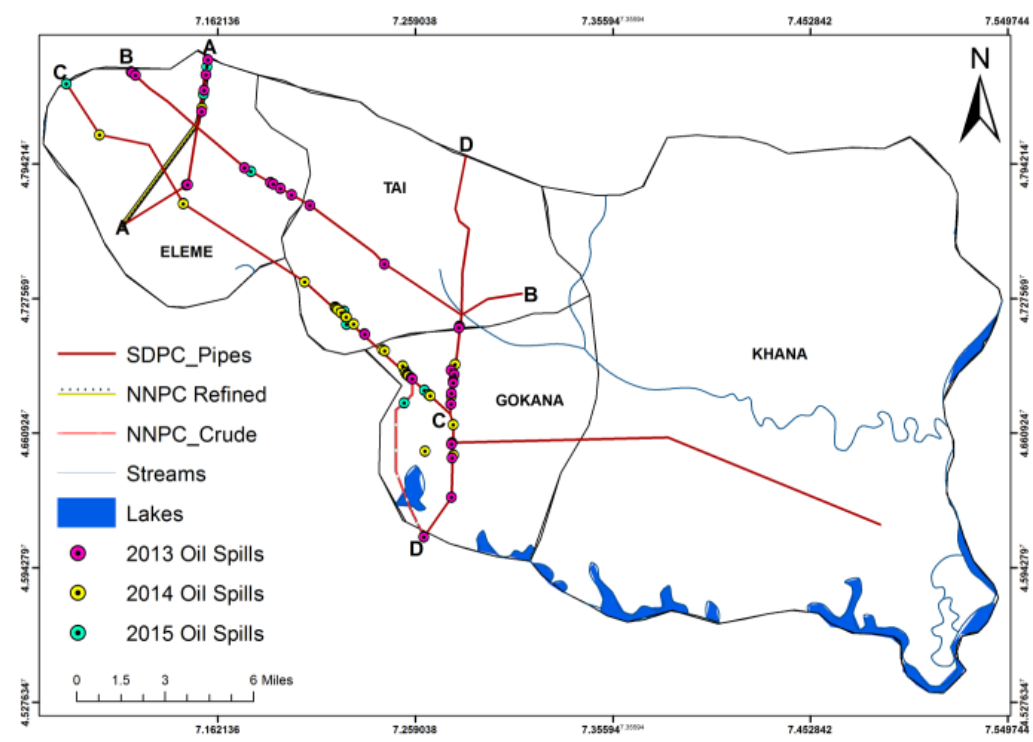

Fig.3: Temporal map of oil spill

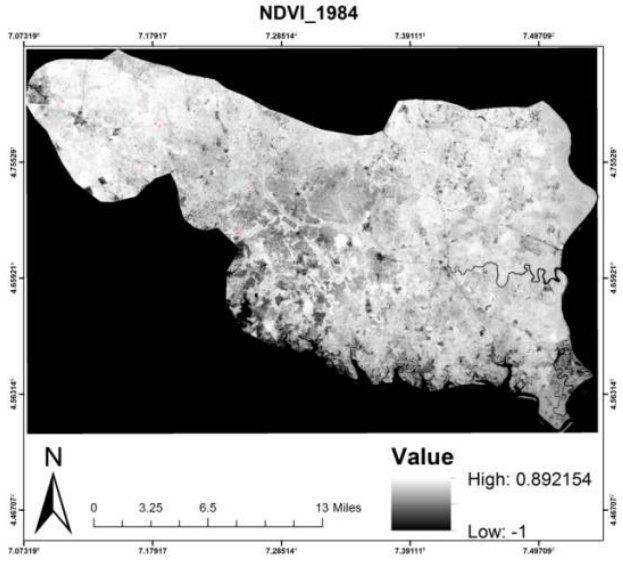

a

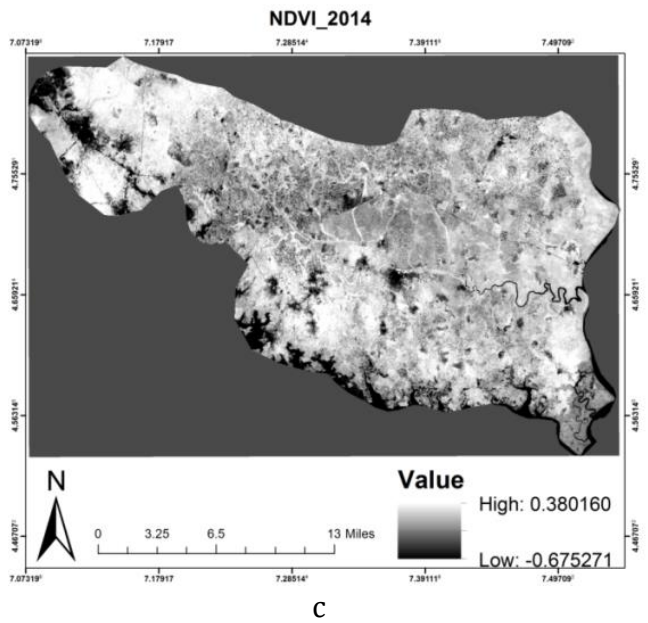

Fig 4: NDVI Image (a) 1984 (b) 2013
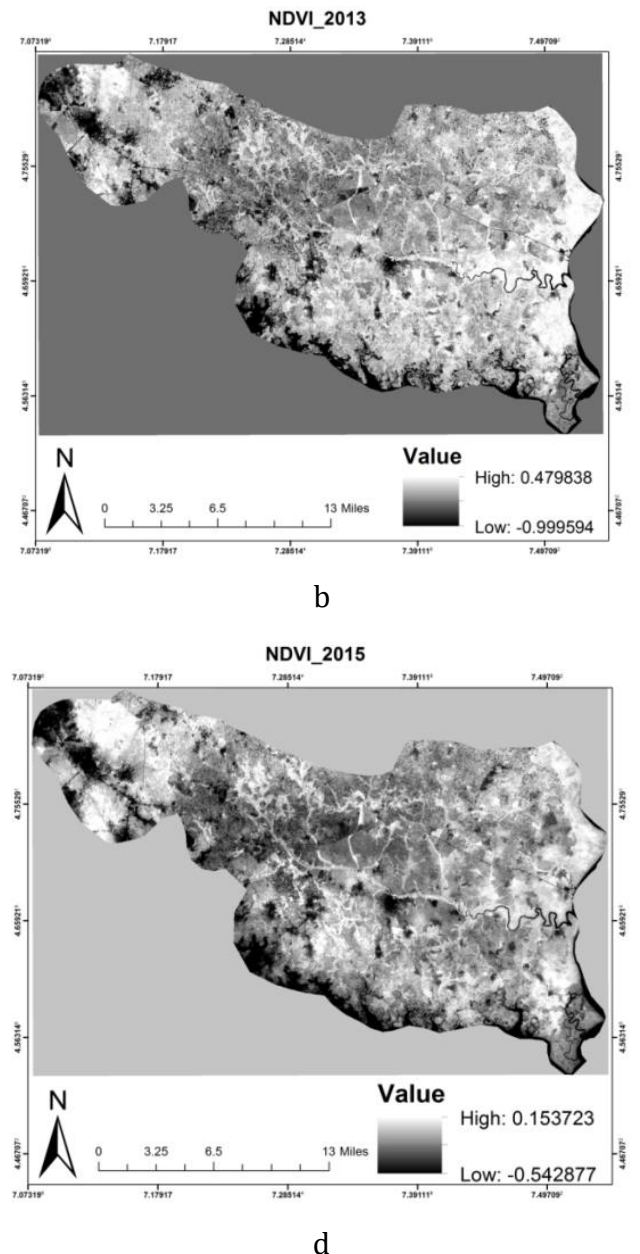

(c) 2014 (d) 2015
Similarly, Table 2 shows the spill points and the NDVI of Landsat 7ETM+ 2014 and the corresponding NDVI of the reference image, and Table 3 shows the spill points and the NDVI of Landsat 7ETM+2015 and the corresponding NDVI of the reference image. In
Tables 1, Table 2, and Table 3, the NDVI values are much lower in almost all the spill points than the NDVI values in the reference image. This indicates the loss in the greenness of vegetation in the affected 
areas which can be attributed to the sensitivity of red and NIR bands to vegetation changes.

In Table 1, Spill point (SP) 8 and SP9 have the same NDVI values, and SP22 and SP23 also have the same NDVI values. This is an indication of a persistent spill point where more than one spill has occurred at the same point. The spill points with NDVI values in 2013 that show maximum difference compared to the reference image are SP17, SP19 and SP33. This indicates the areas with highest vegetation loss. On the other hand, several spill points in Table 2 have similar NDVI values which could be due to geographical closeness. For example SP4 spill which occurred in Tai in November and spills of SP5 and SP6 which occurred in Eleme on the same day in January have the same NDVI values. This is an indication that the land cover types within these areas are either similar or exactly the same. Similarly spills of SP7 and SP8 of January in Eleme, SP24 and SP25 of April, SP29 in June, SP31 of November, SP34 of January and SP35 in July, all in Gokana have the same NDVI values. Table 3 shows that the NDVI of spill points in 2015 are extremely lower compared to the reference image where only three spill areas have positive NDVI values (SP3, SP4, and SP15). All other spill points have negative NDVI meaning that vegetation in 2015 has drastically lost its greenness compared to 2013 and 2014.

Table 1: NDVI of 1984 and 2013 for spill points (2013)

\begin{tabular}{|c|c|c|}
\hline Spill Points & NDVI 1984 & NDVI 2013 \\
\hline SP1 & 0.262952 & 0.200211 \\
\hline SP2 & 0.277975 & 0.17095 \\
\hline SP3 & 0.23394 & 0.200211 \\
\hline SP4 & 0.2070981 & 0.09939 \\
\hline SP5 & 0.240912 & 0.050144 \\
\hline SP6 & 0.161343 & 0.090484 \\
\hline SP7 & 0.343717 & 0.139466 \\
\hline SP8 & 0.240912 & 0.173702 \\
\hline SP9 & 0.240912 & 0.173702 \\
\hline SP10 & 0.284491 & 0.082264 \\
\hline SP11 & 0.309108 & 0.167847 \\
\hline SP12 & 0.223048 & 0.112626 \\
\hline SP13 & 0.223048 & 0.183732 \\
\hline SP14 & 0.176501 & 0.18772 \\
\hline SP15 & 0.233699 & 0.05233 \\
\hline SP16 & 0.197062 & 0.057329 \\
\hline SP17 & 0.22412 & -0.138147 \\
\hline SP18 & 0.103888 & 0.05233 \\
\hline SP19 & 0.04538 & -0.044363 \\
\hline SP20 & 0.130001 & 0.001357 \\
\hline SP21 & 0.124546 & 0.049196 \\
\hline SP22 & 0.185329 & 0.027619 \\
\hline SP23 & 0.185329 & 0.027619 \\
\hline SP24 & 0.181298 & 0.091707 \\
\hline SP25 & 0.14141 & 0.109326 \\
\hline SP26 & 0.097106 & 0.082264 \\
\hline SP27 & 0.077982 & 0.085968 \\
\hline SP28 & 0.185838 & 0.015694 \\
\hline SP29 & 0.177487 & 0.057329 \\
\hline SP30 & 0.159256 & 0.08665 \\
\hline SP31 & 0.259439 & 0.063474 \\
\hline SP32 & 0.203887 & 0.174964 \\
\hline SP33 & 0.153031 & -0.040007 \\
\hline SP34 & 0.196578 & 0.021665 \\
\hline
\end{tabular}

Based on Tables 1, Table 2, and Table 3, it was observed that spill points in 2013 have higher variation in vegetation quality with the reference image, than 2014 spill points, and in 2015 vegetation was highly degraded. This means that the reduction in vegetation reflectance is not sequential but irregular. In order to understand the variations in the NDVI of the three years with the reference image, a plot of the variations is shown in Fig. 5 .

Table 2: NDVI of 1984 and 2014 for spill points (2014)

\begin{tabular}{|c|c|c|}
\hline Spill Points & NDVI 1984 & NDVI 2014 \\
\hline SP1 & 0.173823 & 0.060246 \\
\hline SP2 & 0.321244 & 0.289017 \\
\hline SP3 & 0.25068 & 0.13124 \\
\hline SP4 & 0.228815 & 0.104582 \\
\hline SP5 & 0.23145 & 0.104582 \\
\hline SP6 & 0.23145 & 0.104582 \\
\hline SP7 & 0.205635 & 0.158486 \\
\hline SP8 & 0.22124 & 0.158486 \\
\hline SP9 & 0.238644 & 0.127154 \\
\hline SP10 & 0.189257 & 0.117083 \\
\hline SP11 & 0.20903 & 0.149498 \\
\hline SP12 & 0.173823 & 0.122677 \\
\hline SP13 & 0.185329 & 0.159902 \\
\hline SP14 & 0.238114 & 0.127154 \\
\hline SP15 & 0.185329 & 0.159902 \\
\hline SP16 & 0.18532 & 0.156802 \\
\hline SP17 & 0.189134 & 0.06759 \\
\hline SP18 & 0.197062 & 0.064858 \\
\hline SP19 & 0.165949 & 0.104582 \\
\hline SP20 & 0.189134 & 0.22549 \\
\hline SP21 & 0.222395 & 0.24477 \\
\hline SP22 & 0.226019 & 0.114354 \\
\hline SP23 & 0.196578 & 0.146122 \\
\hline SP24 & 0.162539 & 0.173716 \\
\hline SP25 & 0.162539 & 0.173716 \\
\hline SP26 & 0.162539 & 0.173716 \\
\hline SP27 & 0.161343 & 0.154018 \\
\hline SP28 & 0.162539 & 0.173716 \\
\hline SP29 & 0.135456 & 0.119377 \\
\hline SP30 & 0.135456 & 0.119377 \\
\hline SP31 & 0.135456 & 0.119377 \\
\hline SP32 & 0.072543 & 0.087923 \\
\hline SP33 & 0.143538 & 0.039703 \\
\hline SP34 & 0.157923 & 0.151073 \\
\hline SP35 & 0.157923 & 0.151073 \\
\hline SP36 & 0.203887 & 0.195182 \\
\hline SP37 & 0.22412 & 0.247011 \\
\hline SP38 & 0.192731 & 0.072536 \\
\hline SP39 & 0.243059 & 0.142778 \\
\hline SP40 & 0.229407 & 0.192911 \\
\hline 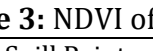 & & NIDU 2015 \\
\hline Spill Points & NDVI 1984 & NDVI 2015 \\
\hline SP1 & 0.245704 & -0.141488 \\
\hline SP2 & 0.162539 & -0.057453 \\
\hline SP3 & 0.321252 & 0.054198 \\
\hline SP4 & 0.26992 & 0.001263 \\
\hline SP5 & 0.082188 & -0.01023 \\
\hline SP6 & 0.127075 & -0.099212 \\
\hline SP7 & 0.189257 & -0.066892 \\
\hline SP8 & 0.193022 & -0.136732 \\
\hline SP9 & 0.153031 & -0.136732 \\
\hline SP10 & 0.076159 & -0.151048 \\
\hline SP11 & 0.157923 & -0.058975 \\
\hline SP12 & 0.094831 & -0.077431 \\
\hline SP13 & 0.022096 & -0.041268 \\
\hline SP14 & 0.173823 & -0.018561 \\
\hline SP15 & 0.213515 & 0.028776 \\
\hline SP16 & 0.151469 & -0.037748 \\
\hline
\end{tabular}

The variation of NDVI in Fig. 5a of spill points in 2013 compared to the reference NDVI shows high decrease in reflectance (NDVI) at SP17, SP19 and SP32, while in Fig. 5b, SP33 is the least vegetative point compared to the reference NDVI. Nevertheless, the reflectance at some point in 2014 is even higher than the reference image. The Variations between 
the temporal NDVI may be attributed to the type of land cover or terrain, frequency of rainfall etc.

The variation between NDVI of spill points in 2015 (Fig. 5c) and the reference image differ significantly because almost all the values are negative. The observed variations based on the changes in vegetation quality using NDVI which is in line with the findings of Noomen et al. (2012), Adamu et al. (2013) and Van der meer et al. (2002) showed that vegetation at oil polluted areas have lower NDVI compared to unpolluted areas.

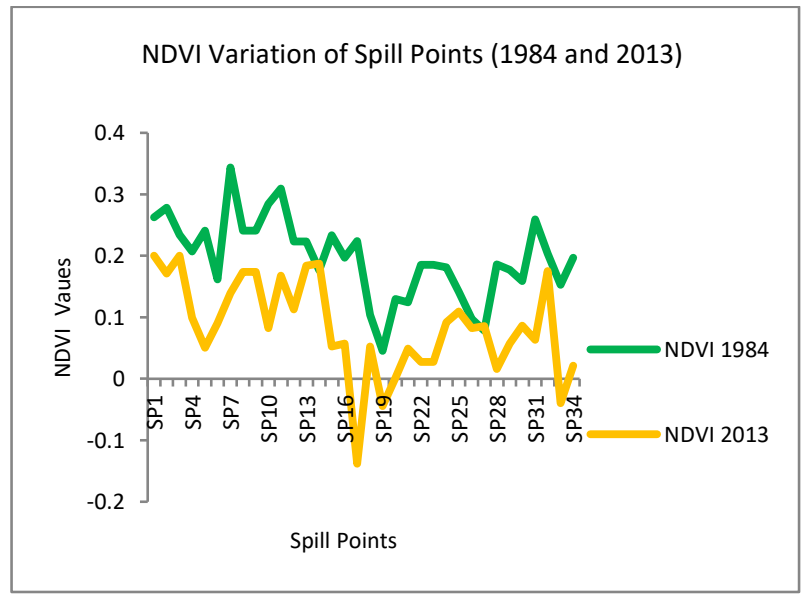

a

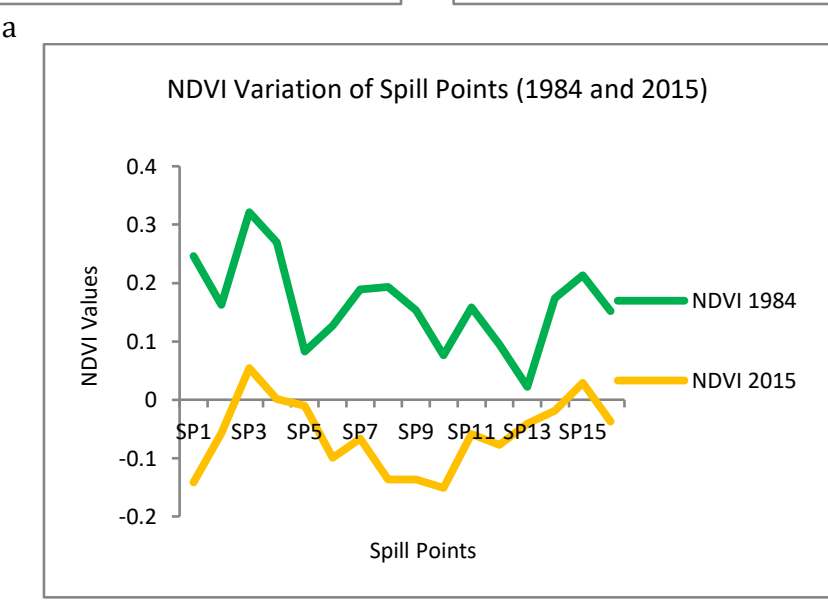

NDVI Variation of Spill Points (1984 and 2014)

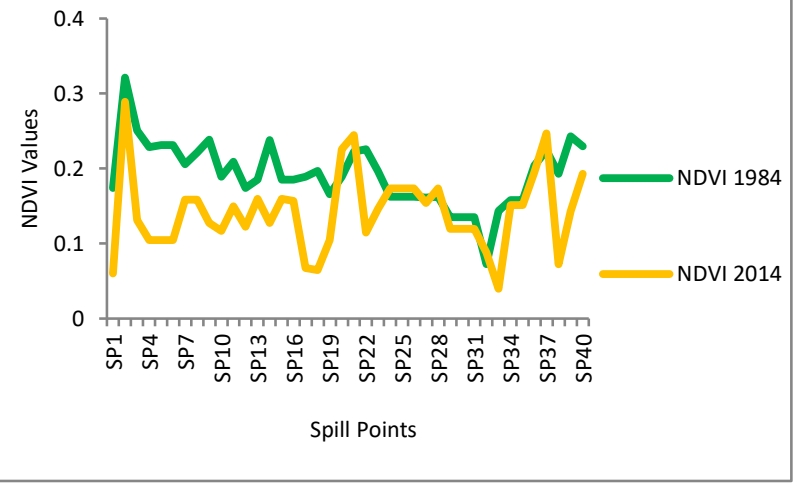

b

and 2013 (b) 1984 and 2014 (c) 1984 and 2015

\subsection{Statistical analysis}

Statistical analysis was used in this study to bring out the value of investigating vegetation changes at oil spill locations. To analyze the changes, statistics was used in three different forms in order to make meaningful observations on how the variations and relationships are distributed among the three years. The first form was the use of statistical curves which were plotted from the derived statistical NDVI values. The curves in Fig. 6 show the differences in the mean, standard deviation (SD), minimum and maximum values of the spill points in the three years and the corresponding NDVI values in the reference points. This part of the analysis indicated the degree of vegetation quality, ranging from the highest to the lowest based on minimum, maximum, mean and SD. In this case, not much can be said about the mean and the SD possibly due to the type of analysis. The trend shows that, vegetation quality reduces with increase in years, with the most vital vegetation in 1984 and it reduced with time. By 2015, much of the vegetation has almost been reduced to bare surface.

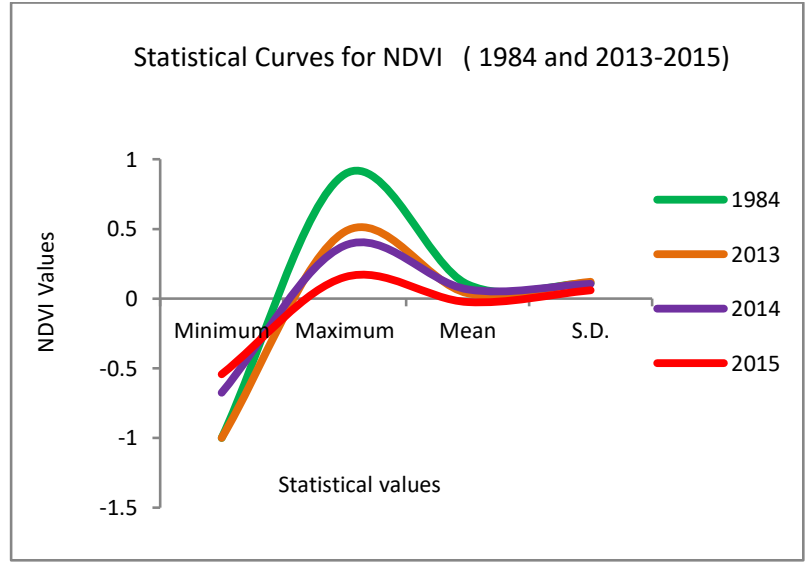

Fig. 6: Statistical curves of vegetation quality

The second form of statistical variation and relationship analysis is the use of mean and SD of the NDVI of reference image and that of the other three images as shown in Fig. 7. Three advantages were observed after comparing the mean and SD; the first one is that the measure of SD is better illustrated in Fig. 7 than in Fig. 6 where the minimum and maximum values where included. In Fig. 7, the mean 
and SD are closest in 1984 (although higher than the mean) and farthest in 2015 because 1984 has lowest difference between the mean and SD while 2015 is not only low but negative. The high SD (0.12) in 2013 means high amount of variation with the SD being three times the mean (0.04). Overall, the mean is lower than the SD throughout the four years indicating high variation.

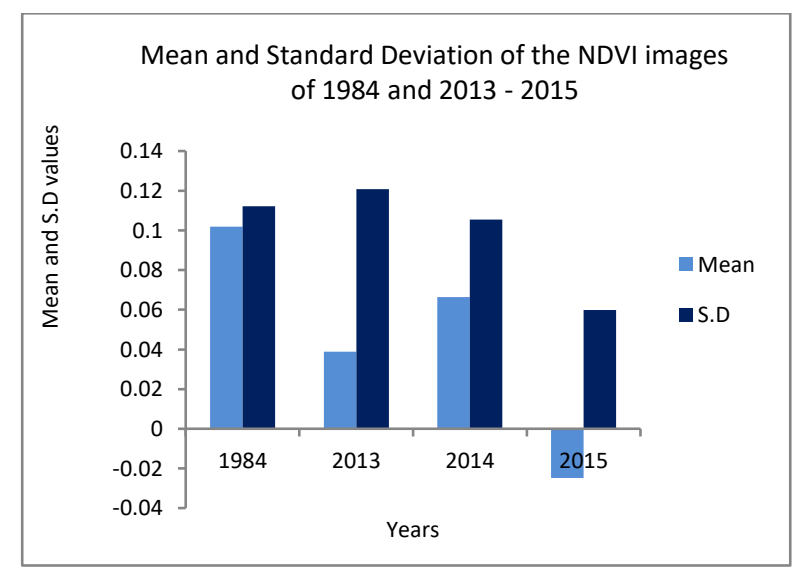

Fig. 7: Statistical chart of mean and SD

The final type of statistical measure used is the correlation analysis of the differences temporally. The scatter plots (Fig. 8) shows three different plots of change values (NDVI difference values for 2013, 2014 , and 2015) presented respectively in order to find the correlation between the change and the spill points in each year. The first plot (Fig. 8a) shows that there is no specific relationship, and this is indicated by points scattered almost horizontally to the spill point axis. This means that regardless of how high the change in vegetation (NDVI) is, the spill points do not vary systematically or accordingly. Precisely, higher differences in NDVI do not mean that there are many spill points or spill occurrences.

It is apparent that in Fig. 8b, the NDVI changes and the spill points are more or less negatively correlated, even though some points in the correlation look weak. This indicate that that there are more oil spills but lower NDVI change contrary to Fig. 8a with lower number of spills and higher NDVI change.

In Fig. 8c, the nature of change is similar to that of Fig 8a, but is even more prominent where the number of spills is least, but vegetation change is highest. Considering the strength of the relationship between the changes in the three periods, it can be estimated by visually analyzing the scatter plots. Fig. $8 \mathrm{a}$ and $\mathrm{c}$ are similar in magnitude of their relationship because the points are spread around different directions and extents.

In Fig. 8b, points fall more tightly together than the other two from higher left to lower right in a somewhat linear pattern. This closeness to the linear pattern shows that there is a strong negative correlation i.e. the higher the number of spills, the lower the value of change in NDVI. In Fig. 8a and c, points are scattered more than those in Fig. $8 b$ indicating weak correlation. To emphasize that having more oil spills at a point or an area does not indicate having higher change in vegetation, it is noteworthy that in Fig. 8c, which has the least number of spill points, NDVI change is highest. Additionally, the change in NDVI of the first 16 spills in Fig. 8b were compared to the 16 spills in Fig. 8c, and the observation was that there is higher difference between the NDVI change with maximum change in Fig. 8c as 0.38719 and that of Fig. $8 \mathrm{~b}$ is lower with a change value of 0.12154 .

In a summary, small number of spills can lead to higher change in vegetation and consequent environmental degradation. However considerations should be made in terms of quantity of oil spilled or the type of land cover present at the spill points before making decisions. For example in the case of landcover type, it could happen that the spill points are located on bare land/open areas (which have very low NDVI values) where very low change is expected. Similarly, low NDVI change will be expected in areas with high vegetation quality and but little amount of oil spilled. The example could be vice versa; say oil spills in forest areas (high NDVI change is expected).

\section{Conclusion}

Four different approaches were used in this study to determine the logic behind the perception that high environmental degradation in Ogoniland is caused by the alarming number of oil spills. Although the four approaches were used for the same objectives, they have all shown their potentials in bringing out the varied relationships between vegetation change and the spill points. The outcomes were intrinsic to each method such that each method revealed a different output although all highlighting the degree of variation. The NDVI variation showed that vegetation at later time (2013, 2014, and 2015) has lower NDVI compared to the reference image, thus indicating a degraded environment. The variation level was shown which is highest in 2015 and lowest in 1984. The statistical curves on the other hand show the decrease in the quality of vegetation with time. The Mean and SD comparison showed the measure of SD. The scatter plot which involved the plot of the difference values showed that there is negative correlation between the changes in vegetation and the number of spills in each year.

It was however concluded that oil spill is one of the causes of environmental degradation in Ogoniland, but the level of degradation cannot be ascribed to the number of spills. It is possible that there are other factors that contribute to the decrease in environmental quality.

Most Studies yielded insights into the land cover change analysis (Abbas and Fasona, 2012; Twumasi and Merem, 2006) and the use of vegetation indices to detect and indicate land degradations caused by oil spills (Adamu et al., 2013; Uchegbulam and Ayolabi, 2013). However, this study has provided an 
additional requirement for monitoring of oil spills

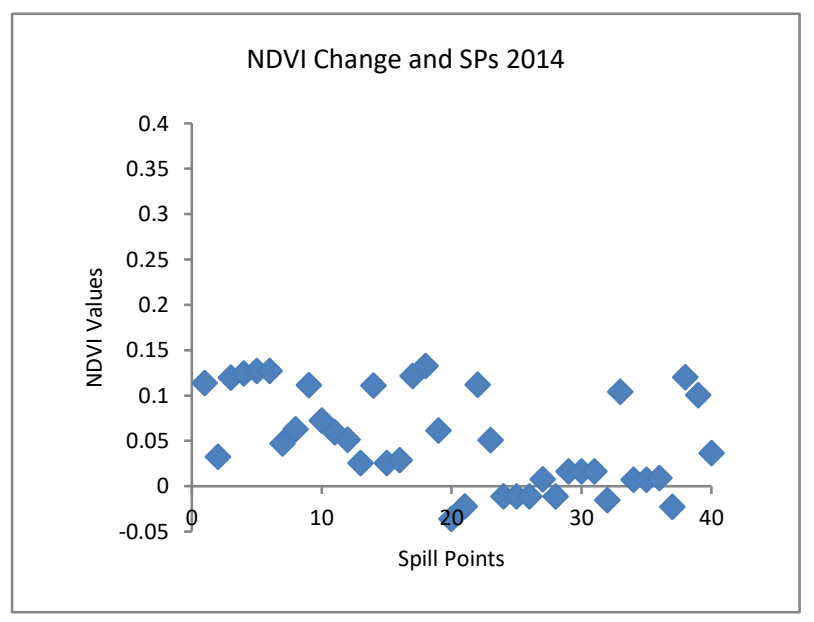

using remote sensing and GIS.

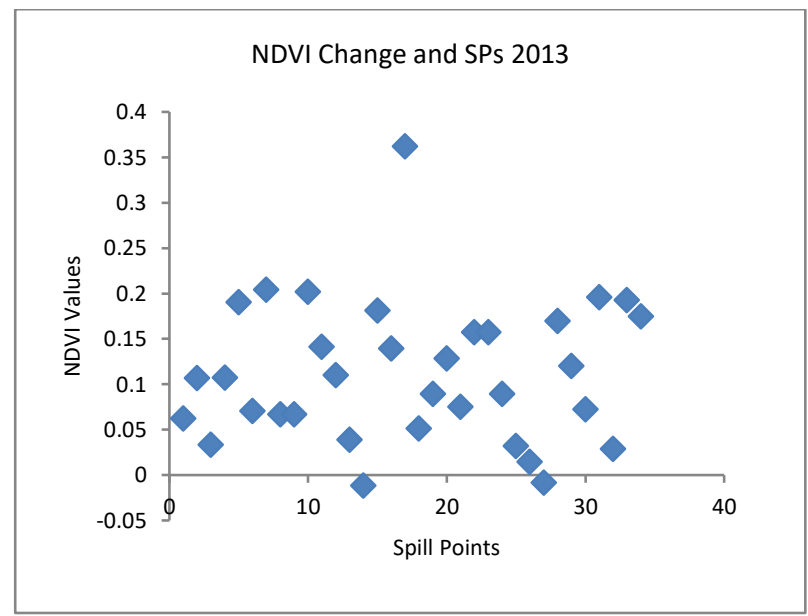

a

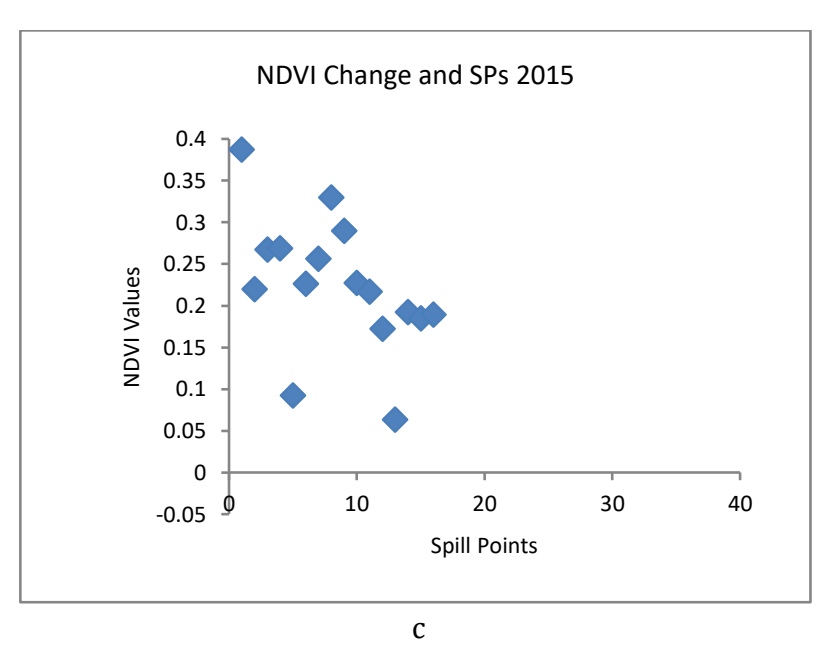

Fig. 8: Correlation of NDVI change and spill location (a) 2013 (b) 2014 (c) 2015

\section{Acknowledgement}

This study was funded by the Universiti Teknologi Malaysia Research Grant (Q.J130000.2527.12H65). We would also like to express our thanks to National Oil Spill Detection and Response Agency (NOSDRA) Nigeria, The United Nations Environmental Program (UNEP, 2011) and U.S. Geological Survey for data used.

\section{References}

Abbas II and Fasona MJ (2012). The human perception of land degradation in a section of Niger Delta, Nigeria. Marine Science, 2(5): 94-100.

Adami G, Cabras I, Predonzani S, Barbieri P, and Reisenhofer E (2007). Metal pollution assessment of surface sediments along a new gas pipeline in the Niger Delta (Nigeria). Environmental Monitoring and Assessment, 125(1): 291-299.

Adamu B, Tansey K, and Bradshaw MJ (2013). Investigating vegetation spectral reflectance for detecting hydrocarbon pipeline leaks from multispectral data. In the SPIE Conference of Remote Sensing, International Society for Optics and Photonics, Dresden, Germany. https://doi.org/10.1117/12. 2028907

Adamu B, Tansey K, and Ogutu B (2014). Detection of oil pollution along the pipeline routes in tropical ecosystem from multispectral data. In the SPIE Conference of Sensing Technology+ Applications, International Society for Optics and Photonics.
Baltimore, USA: 91210D-91210D. https://doi.org/10.1117/ 12.2049590

Adamu B, Tansey K, and Ogutu B (2015). Using vegetation spectral indices to detect oil pollution in the Niger Delta. Remote Sensing Letters, 6(2): 145-154.

Adegoke JO, Fageja M, James G, Agbaje G, and Ologunorisa TE (2010). An assessment of recent changes in the Niger Delta coastline using satellite imagery. Journal of Sustainable Development, 3(4): 277-296.

Anifowose B, Lawler D, Van der Horst D, and Chapman L (2008). Transportation in Nigeria's oil \& gas industry: An environmental challenge. In the $1^{\text {st }}$ Conference of Meeting Environmental Challenges in the Coastal Region of Nigeria (GEES'08), Earth \& Environmental Sciences, Dundee, UK. Available online at: https://www.researchgate.net/profile /Damian_Lawler/publication/252627090_Transportation_in_ Nigeria\%27s_Oil_Gas_Industry_an_Environmental_Challenge/l inks/02e7e51f3d039098b4000000/Transportation-inNigerias-Oil-Gas-Industry-an-Environmental-Challenge.pdf

Brekke C and Solberg AH (2005). Oil spill detection by satellite remote sensing. Remote Sensing of Environment, 95(1): 1-13.

Fatoyinbo TE and Simard M (2013). Height and biomass of mangroves in Africa from ICESat/GLAS and SRTM. International Journal of Remote Sensing, 34(2): 668-681.

Fingas M (2012). The basics of oil spill cleanup. CRC Press, Boca Raton, USA.

Hese S and Schmullius C (2009). High spatial resolution image object classification for terrestrial oil spill contamination mapping in West Siberia. International Journal of Applied Earth Observation and Geoinformation, 11(2): 130-141. 
Ibeanu 0 (2000). Oiling the friction: Environmental conflict management in the Niger Delta, Nigeria. Environmental Change and Security Project Report, 6(6): 19-32.

James GK, Adegoke JO, Saba E, Nwilo P, and Akinyede J (2007). Satellite-based assessment of the extent and changes in the mangrove ecosystem of the Niger Delta. Marine Geodesy, 30(3): 249-267.

Noomen MF, van der Werff HM, and van der Meer FD (2012). Spectral and spatial indicators of botanical changes caused by long-term hydrocarbon seepage. Ecological Informatics, 8: 5564.

Onojeghuo AO and Blackburn GA (2011). Forest transition in an ecologically important region: Patterns and causes for landscape dynamics in the Niger Delta. Ecological Indicators, 11(5): 1437-1446

Onwurah INE, Ogugua VN, Onyike NB, Ochonogor AE, and Otitoju OF (2007). Crude oil spills in the environment, effects and some innovative clean-up biotechnologies. International Journal of Environmental Research, 1(4): 307-320.

Pitkin J (2013). Oil, oil, everywhere: Environmental and human impacts of oil extraction in the Niger Delta. Panoma Senior Theses, Pomona College, Claremont, USA
Reible D (2010). After the oil is no longer leaking. Environmental Science and Technology, 44(15): 5685-5686.

Shell (2015). Spill Incident Data; Shell Petroleum Development Company, Abuja, Nigeria. Available online at: http://www.shell. com.ng/sustainability/environment/oil-spills.html

Twumasi YA and Merem C (2006). GIS and remote sensing applications in the assessment of change within a coastal environment in the Niger Delta Region of Nigeria. International Journal of Environmental Research and Public Health, 3(1): 98-106.

Uchegbulam 0 and Ayolabi EA (2013). Satellite image analysis using remote sensing data in parts of Western Niger Delta, Nigeria. Journal of Emerging Trends in Engineering and Applied Sciences, 4(4): 612-617.

UNEP (2011). Environmental assessment of Ogoniland. United Nations Environmental Programme, Nairobi, Kenya.

Van der Meer F, Van Dijk P, Van Der Werff H, and Yang H (2002). Remote sensing and petroleum seepage: a review and case study. Terra Nova, 14(1): 1-17. 